\title{
ACCESSORY LOBE OF LIVER PRESENTING THROUGH A CONGENITAL DEFICIENCY OF ANTERIOR ABDOMINAL WALL
}

\author{
BY \\ GEORGE JOHNSTONE \\ From Muhimbili Hospital, Dar es Salaam, Tanzania \\ (RECEIVED FOR PUBLICATION JANUARY 4, 1965)
}

\begin{abstract}
Abnormalities of the liver, though varied, are rare, are of little clinical importance, rarely require treatment, and are usually discovered at necropsy. The case about to be described confutes the latter statements, because the abnormality was obvious at birth and required treatment. Meckel (1822) reported several cases of accessory lobes of the liver. Jacquemet (1896) and Forni (1915) reviewed the published material. Cullen (1925) in an exhaustive review mentioned 91 cases. This article deals with an African child born with an accessory lobe of the liver projecting through a hiatus in the upper anterior abdominal wall. In addition the child had solitary dextrocardia and two nipples on the left side.
\end{abstract}

\section{Case Report}

On October 21, 1963, a female African child was seen 5 hours after birth with a bluish-red sausage-like mass projecting through a gap in the left lower thoracic region (Fig. 1). It appeared between two nipples, of which one was slightly higher and the other considerably lower than the right nipple. There was granulation tissue at the lower end of the gap through which the mass projected (Fig. 2). There was no bleeding or discharge and the mass could be reduced within the integuments. It was not possible to say from where it was arising nor from which cavity. The site of the gap and the colour of the mass gave rise to the erroneous impression that this was herniated collapsed lung tissue. The heart was displaced to the right side. The child otherwise appeared to be healthy.

Operation. At operation on October 23, the mass was reduced and it was seen that the edges of the gap were fused and that there were exuberant granulations at the lower end. An incision was made over the lower ribs to include the edges of the gap. The pleural cavity was opened and a normal inflated lung was found. The pleural cavity was closed and the original incision extended downwards as an upper paramedian incision. The abdominal cavity was entered and the mass was found to be projecting from the antero-superior border of the left lobe of the liver (Fig. 3). The mass, which was broader at the base than at the tip, was approximately $5 \mathrm{~cm}$. long by $2 \mathrm{~cm}$. broad at the base. The outer layer was continuous with the surface of the liver but there was a marked colour change between the liver and the pro-

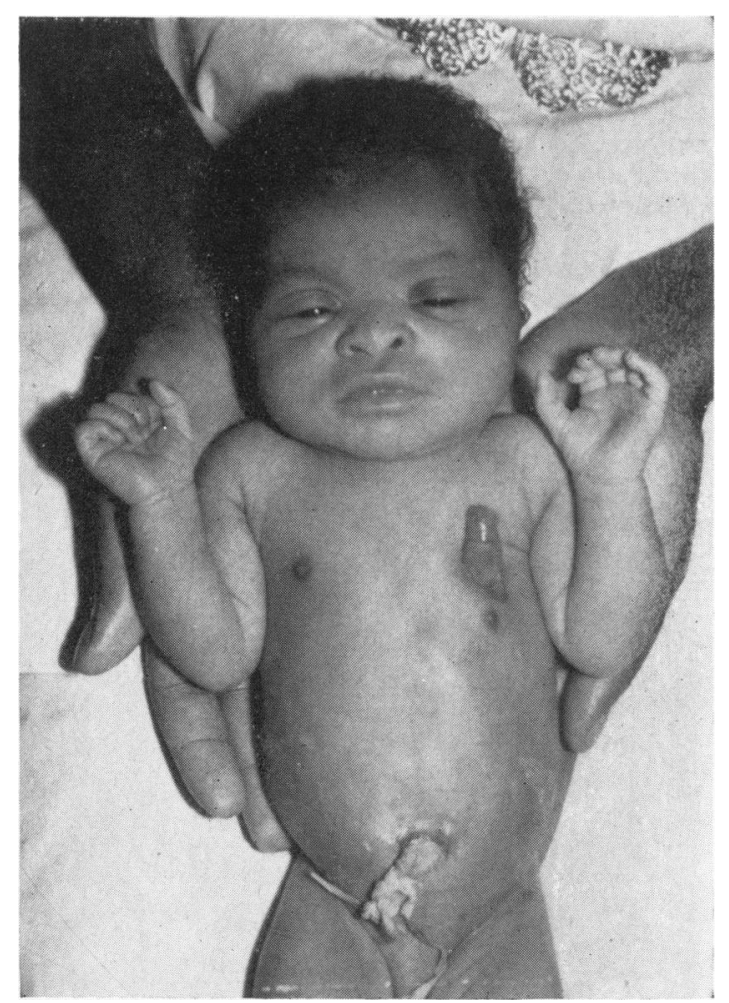

Fig. 1.-Shows the child shortly after birth with the abnormal lobe projecting on the left side above the inferior nipple. Superior nipple obscured. 


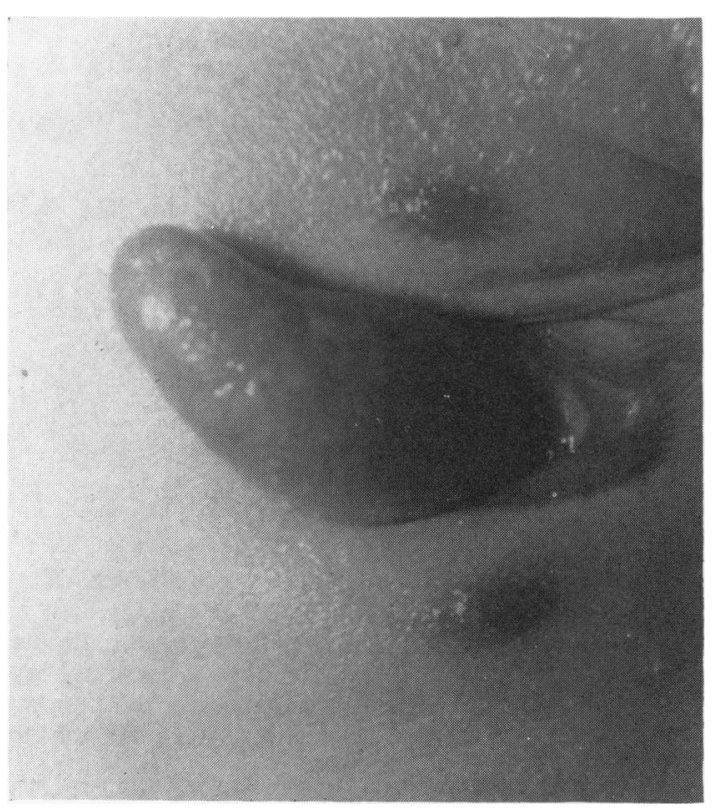

FIG. 2.-The liver projection has moved medially. Both nipples shown, also the exuberant granulation tissue at the lower end of the hiatus.

jection. The mass was transfixed, ligated at its base, and then excised. No other abnormalities of the liver were discovered. The wound was closed in layers.

Post-operative. A chest radiograph 3 days after operation showed that the left lung was expanded and that the heart was still on the right side.

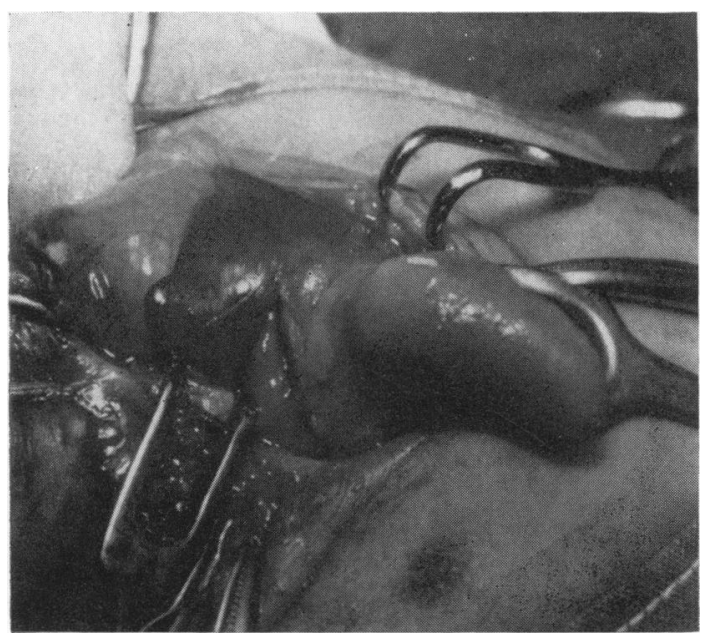

FIG. 3.-At operation. Shows the abnormal lobe arising from the antero-superior surface of the left lobe of liver. Note marked colour change between abnormal projection and normal liver.
Histology. Sections of the tissue showed an outer layer of necrosis with a deeper layer of granulation tissue. Deep to this again there was recognizable normal liver tissue with a polymorph infiltration which gradually lessened in the depths of the tissue.

The post-operative convalescence was uneventful and the child was discharged with a well-healed wound on November 2, 1963. She was readmitted on November 20, 1963. A barium meal with follow-through showed that there were no abnormalities of rotation of the gut. Electrocardiograms were inconclusive. The child was again seen at 7 months of age. Chest radiograph showed persistent dextrocardia (Fig. 4). The child's general condition was good (Fig. 5). She measured 24 in. $(61 \mathrm{~cm}$.) in length and weighed $12 \mathrm{lb} .3 \mathrm{oz} .(5 \cdot 5 \mathrm{~kg}$.). There was a depression of the chest wall at the site of incision, and both left nipples were smaller than the one on the right side. The sclerotics were a light china blue but there was no evidence of cyanosis.

\section{Discussion}

The child when first seen was 5 hours old, and despite the abnormalities her general condition was good. The bluish-red mass projected upwards and towards the left from the gap in the left hypochondrium. It was mobile and easily reduced within the body cavity. Difficulty in diagnosis arose because of the site and the colour. Intra-abdominal examination was kept to a minimum, but if it had been more extensive then there is little doubt that an accurate diagnosis could have been made.

No explanation for this abnormal projection from an apparently otherwise normal liver can be given. As the result of occupying an abnormal position and being outside the normal habitat of the liver the surface was necrotic, but the deeper tissues were protected by the formation of granulation tissue. The granulation tissue had spread on to the normal liver surface but stopped abruptly at a line where the liver was protected from external influences. There was a marked colour change at the junction of the abnormal projection with the liver.

The liver, in the developing embryo, occupies most of the space of the upper abdominal cavity. At the $35 \mathrm{~mm}$. stage it is approximately $10 \%$ of the body weight. After this the growth rate diminishes, the left lobe growing more slowly than the right, so that at birth the liver is only $5 \%$ of the body weight (Hamilton, Boyd, and Mossman, 1962). The left lobe is directly related to the anterior abdominal wall in a small area of the epigastrium in the left substernal angle (Hollinshead, 1956). This abnormal projection would therefore be in direct contact with the developing anterior abdominal wall. The somatopleure is very thin and transparent. Thickening starts dorsally and advances ventrally until in the late embryonic period there is only a 


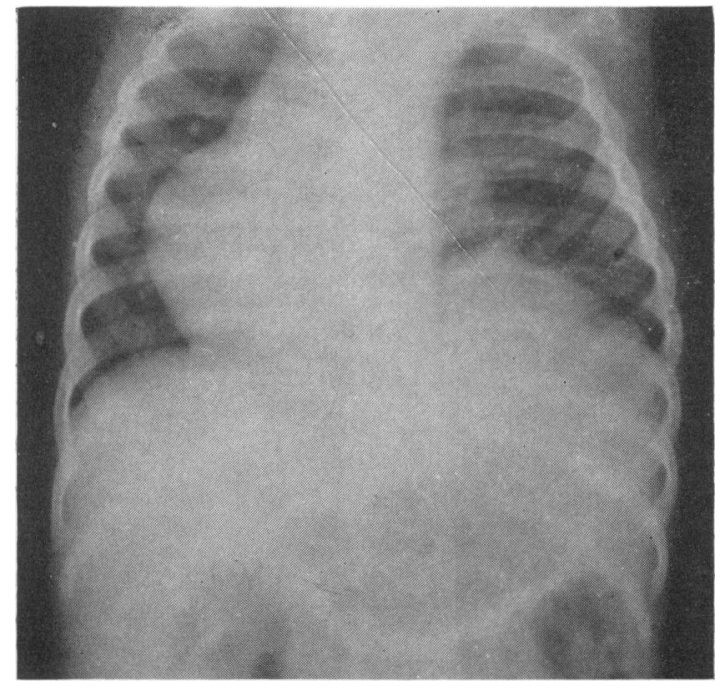

FIG. 4.-Chest radiograph of May 22, 1964, shows persistent dextrocardia.

broad diamond-shaped transparent area around the attachment of the umbilical cord (Hamilton et al., 1962). As the hiatus in the child's anterior abdominal wall had fused edges one can only presume that the abnormal lobe of liver perforated and projected through the somatopleure and thus prevented the development and ultimate fusion of the elements of the anterior abdominal wall.

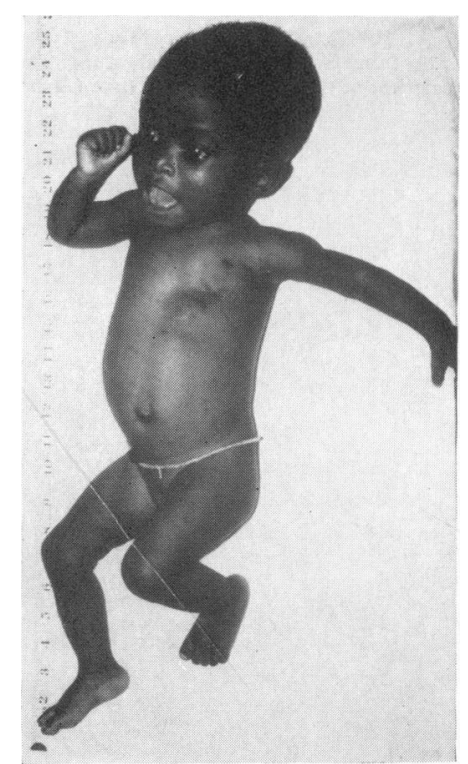

Fig. 5.-The child at 7 months of age. Note depression at centre of well-healed scar.
Though the gap in the anterior abdominal wall is directly attributable to the abnormal lobe of liver, there appears to be no relation between these abnormalities, the dextrocardia, and the multiple nipples. The nipples were left pending future developments and elective surgery.

The dextrocardia appears to be the rare variety of isolated congenital dextrocardia in which the other viscera are in the normal position. This variety is usually associated with grave cardiac anomalies. The latter have not, so far, been found in this child.

Anomalies in the size and shape of the liver are common but accessory lobes less so. Abnormalities are usually discovered at necropsy or, occasionally, at operation. Cullen (1925) listed the abnormalities as (1) diminution in size of one or more lobes, (2) hypertrophy of one or more lobes, (3) marked furrowing, (4) marked lobulation, (5) Riedel's lobe, (6) thoracic displacement of the liver through a congenital deficiency in the diaphragm, (7) accessory lobes, either attached directly to the liver by hepatic tissue or by a mesentery, (8) part of the liver appearing in an amniotic hernia, (9) accessory lobes arising from the gall-bladder, and (10) liver tissue embedded in the suprarenal gland.

Messing and Ashley-Montagu (1932) reported the absence of the left lobe, and Wakefield (1899) reported a congenital malformation with absence of the Spigellian lobe, rudimentary quadrate and left lobes, and an enlarged right lobe. Chouke (1932) reported an anomalous lobe of the liver. All these were discovered at necropsy. Friedman, SolisCohen, and Levine (1947) made a radiological diagnosis of an accessory lobe arising from the superior surface of the right lobe of the liver by means of a diagnostic pneumoperitoneum.

Riedel's lobe is the commonest abnormality of the liver. Thoracic displacement of the liver through a congenital gap in the diaphragm is usually incompatible with life, and where part of the liver appears in an amniotic hernia resection of part of the liver may be necessary before the abdominal contents can be reduced.

Accessory lobes of the liver are subdivided into (1) those attached to the liver by a pedicle of liver tissue and (2) those connected to the liver by a mesentery (Cullen, 1925). For their viability it is essential that accessory lobes have a hepatic artery, hepatic vein, portal vein, and a bile-duct. They usually communicate through the liver but occasionally they have made systemic connexions outside of the liver. The case reported had a sessile attachment to the antero-superior border of the left lobe of the liver and presumably had the necessary arteries, veins, and duct. The accessory lobes arising from 
the gall-bladder may be attached either by a pedicle or a mesentery.

Accessory lobes of the liver are of little clinical importance because they are usually situated on the deep surface of the liver, cause no disturbance, and do not require to be removed. However, the case being reported required treatment because of the exteriorization of the abnormal lobe and the gap in the upper abdominal wall. In Inglis' (1911) case the accessory lobe was palpable during life, appeared to expand and pulsate, but as it caused no pain or discomfort was left alone, and its nature was only discovered at necropsy. Cullen (1925) reported a case with recurrent epigastric pain, nausea, vomiting, and faintness, where at operation the fibrous pedicle of an accessory lobe from the right lobe of the liver had undergone strangulation due to twisting of the pedicle.

Calori's (1880) case had supernumerary digits on the right foot and in the case quoted by Cullen (1925), where liver tissue was found embedded in one of the suprarenals, there were congenital cardiac abnormalities. The present case has a supernumerary nipple on the left side and there is radiological evidence of isolated dextrocardia but so far congenital defects of the heart have not been detected and the child remains well.

\section{Summary}

The case of a newborn child with an accessory lobe of the liver, a hiatus of the anterior abdominal wall, isolated dextrocardia, and multiple nipples is presented. The development of the liver and abdominal wall is considered and the available published material on abnormalities of the liver is reviewed. The significance of isolated dextrocardia is mentioned, and it is noted that liver abnormalities are usually only discovered at necropsy.

I wish to thank Dr. W. J. Maelor Evans, Chief Medical Officer, Ministry of Health, Tanzania, for his permission to publish this article and Dr. G. Rutledge for referring the patient. I also wish to express my thanks and appreciation to Drs. P. Grech, M. T. Maletnlema, Eccles, and G. A. S. Kombe for their help, and Dr. J. Hamerton for the photographs.

\section{REFERENCES}

Calori, L. (1880). Sulla coesistenza di un' eccessiva divisione del fegato e di qualche dito soprannumerario nelle mani o nei piedi. Mem. R. Accad. Bologna, 2, 335.

Chouke, K. S. (1932). A note on an anomalous lobe of the liver. Anat. Rec., 53, 177.

Cullen, T. S. (1925). Accessory lobes of the liver. An accessory hepatic lobe springing from the surface of the gallbladder. Arch. Surg., 11, 718.

Forni, G. (1915). Contributo allo studio del cosidetto fegato accessorio. Boll. Sci. med., 3, 106.

Friedman, P. S., Solis-Cohen, L., and Levine, S. (1947). Accessory lobe of the liver and its significance in roentgen diagnosis. Amer. J. Roentgenol., 57, 601 .

Hamilton, W. J., Boyd, J. D., and Mossman, H. W. (1962). Human Embryology, 3rd ed., pp. 241, and 420-421. W. Heffer, Cambridge.

Hollinshead, W. H. (1956). Anatomy for Surgeons, Vol. 2, p. 317. Cassell, London.

Inglis, J. P. P. (1911). Extra extrinsic hepatic lobe. Polyclinic, 15, 9. Jacquemet, M. (1896). Considérations sur les anomalies du foie et des voies bilaires. Thèse de Lyon.

Meckel, J. F. (1822). Tabulae Anatomico-Pathologicae, Fasc. III., p. 14, Tabula XXIV. I. F. Gleditsch, Leipzig.

Messing, A., and Ashley-Montagu, M. F. (1932). A note on a case of complete absence of the left lobe of the liver in man. Anat. Rec., $53,169$.

Wakefield, P. A. (1899). Congenital malformation of the liver: absence of the lobus Spigelii, rudimentary quadrate and left lobes with enlargement of the right lobe. J. Anat. (Lond.), 33, 50. 